\title{
Contribution of Arginine 13 to the Catalytic Activity of Human Class Pi Glutathione Transferase P1-1
}

\author{
Ji-Na Kong, Dong-Hyeon Jo, Hyun-Dong Do, Jin-Ju Lee, and Kwang-Hoon Kong*
}

\author{
Biomolecular Chemistry Lab, Department of Chemistry, College of Sciences, Chung-Ang University, Seoul 156-756, Korea \\ EE-mail: khkong@cau.ac.kr
}

Received June 1, 2010, Accepted July 13, 2010

\begin{abstract}
Arg13 is a conserved active-site residue in all known Pi class glutathione $S$-transferases (GSTs) and in most Alpha class GSTs. To evaluate its contribution to substrate binding and catalysis of this residue, three mutants (R13A, R13K, and R13L) were expressed in Escherichia coli and purified by GSH affinity chromatography. The substitutions of Arg 13 significantly affected GSH-conjugation activity, while scarcely affecting glutathione peroxidase or steroid isomerase activities. Mutation of Arg 13 into Ala largely reduced the GSH-conjugation activity by approximately $85-95 \%$, whereas substitutions by Lys and Leu barely affected activity. These results suggest that, in the GSH-conjugation activity of hGST P1-1, the contribution of Arg 13 toward catalytic activity is highly dependent on substrate specificities and the size of the side chain at position 13. From the kinetic parameters, introduction of larger side chains at position 13 results in stronger affinity (Leu > Lys, Arg > Ala) towards GSH. The substitutions of Arg13 with alanine and leucine significantly affected $k_{\text {cat }}$, whereas substitution with Lys was similar to that of the wild type, indicating the significance of a positively charged residue at position 13. From the plots of $\log \left(k_{\mathrm{cat}} / K_{\mathrm{m}}{ }^{\mathrm{CDNB}}\right)$ against $\mathrm{pH}$, the $\mathrm{p} K_{\mathrm{a}}$ values of the thiol group of GSH bound in $\mathrm{R} 13 \mathrm{~A}, \mathrm{R} 13 \mathrm{~K}$, and R13L were estimated to be $1.8,1.4$, and $1.8 \mathrm{p} K$ units higher than the $\mathrm{p} K_{\mathrm{a}}$ value of the wildtype enzyme, demonstrating the contribution of the Arg13 guanidinium group to the electrostatic field in the active site. From these results, we suggest that contribution of Arg13 in substrate binding is highly dependent on the nature of the electrophilic substrates, while in the catalytic mechanism, it stabilizes the GSH thiolate through hydrogen bonding.
\end{abstract}

Key Words: Arginine 13 residue, Glutathione $S$-transferase, Kinetic parameters, Site-directed mutagenesis, Substrate specificity

\section{Introduction}

Glutathione $S$-transferases (GSTs, EC 2.5.1.18) are a family of multifunctional enzymes that catalyze the conjugation of glutathione (GSH) to a wide variety of carcinogenic, mutagenic, toxic, and pharmacologically active compounds. ${ }^{1}$ This reaction is the first step in the formation of mercapturic acid, a pathway through which harmful xenobiotics and endobiotics are inactivated and eliminated. Certain GSTs can also detoxify lipid and DNA hydroperoxide by their intrinsic peroxidase activity, while others catalyze the isomerization of certain steroids. Additionally, they play an important role in the intracellular transport of numerous hydrophobic non-substrate ligands such as bile acids, billirubin, and a number of drugs.

GSTs are distributed in a wide range of organisms from mammals to Escherichia coli. ${ }^{2}$ Mammalian cytosolic GSTs, which can exist as homo- or heterodimers, are grouped into at least seven distinct classes (alpha, mu, pi, sigma, theta, sigma, kappa, zeta) based on their physical, chemical, immunological, and structural properties. ${ }^{3-5}$ The crystal structures for most classes have been determined and used to implicate several amino acid residues in the catalysis and binding of GSH. ${ }^{6-10}$ The electrophilic substrate-binding site has also been localized; however, the structural basis of the differential electrophilic substrate recognition by the various isozymes is still not well understood. Moreover, there is little information available concerning the precise enzyme-substrate interactions potentially responsible for the catalytic properties of GST, while the identification or specific role of individual residues remains largely unknown.
Arg13 is conserved in all known Pi class GSTs, in most Alpha class GSTs, but not in the Mu and Theta class GSTs. Studies on the 3D-structures of porcine GST P1-1 and hGST P1-1 suggest that Arg13 is located in the G-site (Fig. 1). ${ }^{8,11}$ Much to the contrary, the crystal structure of hGST P1-1 with either $S$-hexylGSH or (9R,10R)-9-(S-glutathionyl)-10-hydroxy-9,10-dihydrophenanthrene revealed that the xenobiotic substrate-binding site (H-site) was approximately half hydrophobic and half hydrophilic, and is defined by the side chains of Tyr7, Phe8, Val10, Arg13, Val104, Tyr108, Asn204, and Gly205 and five water

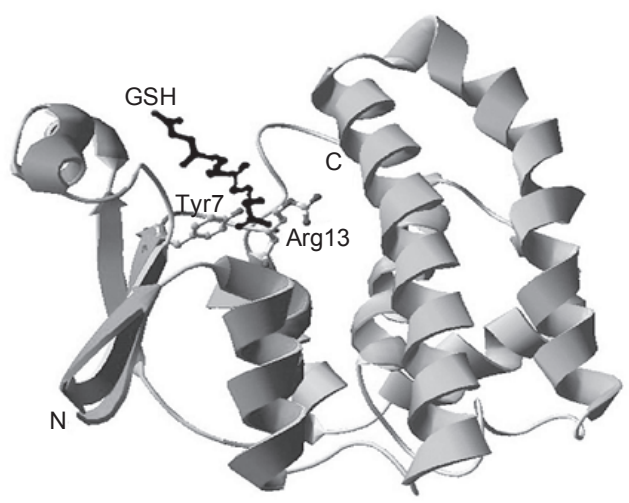

Figure 1. Close view of the active site of human GST P1-1 (Oakley et al., 1997). Schematic representation of a human GST P1-1 monomer showing the location of GSH bound to Tyr7 and Arg13 in a ball-andstick representation. The figure was generated with MOLSCRIPT (Kravlis, 1991). 
molecules. ${ }^{12}$ However, the crystal structure of hGST P1-1 with 7,8-dihydroxy-9,10-oxy-7,8,9,10-tetrahydrobenzo [ $\alpha]$ pyrene suggested that $\operatorname{Arg} 13$ may be able to participate in catalysis. ${ }^{13}$ Taken together, Arg13 of hGST P1-1 is positioned within the active site and is a possible candidate for involvement in catalysis or the binding of the $\mathrm{G}$-site/H-site.

In the present study, to evaluate the contribution of the Arg13 residue of hGST P1-1 to substrate binding and catalysis, we investigated the detailed enzymatic properties and kinetic parameters of R13A, R13K, and R13L mutants. The $\mathrm{p} K_{\mathrm{a}}$ value of the phenolic hydroxyl group of the active site (Tyr7) was determined by spectrophotometric titration of three mutants and shown to be dependent on the amino acid residue at position 13. The results demonstrate that Arg 13 is an important structural moiety that modulates enzyme catalytic efficiency and specificity. This study offers information on the precise enzymesubstrate interactions responsible for the catalytic properties of hGST P1-1, and will be of great value in designing new inhibitors that may prove useful in chemotherapy and new enzymes possessing different substrate specificities. A preliminary version of this work has been presented. ${ }^{14}$

\section{Experimental Section}

Materials. GSH and 1-chloro-2,4-dinitrobenzene (CDNB) were purchased from Kohjin Co. (Tokyo, Japan) and Wako Pure Chem. Ind. (Osaka, Japan), respectively. Cumene hydroperoxide, [2,3-dichloro-4-(2-methylenebutyl)phenoxy]acetic acid (ethacrynic acid : ETA), and $S$-hexylGSH were obtained from Sigma (St. Louis, MO, USA). $\Delta^{5}$-Androstene-3,17-dione was purchased from Steraloids Inc. (Newport, RI, USA). S-(2,4Dinitrophenyl)GSH was synthesized by the method of Schramm et al. ${ }^{15}$ GSH-Sepharose was purchased from Pharmacia Biotech (Uppsala, Sweden). All other reagents used were of the highest grade commercially available and used without further purification, unless otherwise noted.

Preparation of mutant enzymes. Wild-type hGST P1-1 was obtained by expression of a cloned $\mathrm{cDNA}^{16}$ in $E$. coli, as described previously. ${ }^{17}$ The preparation, confirmation, expression, and purification of the mutants R13A, R13K, and R13L were performed as described in the previous paper, ${ }^{14}$ with the exception of purification by affinity chromatography on GSH-Sepharose. The mutant enzymes were expressed in E. coli under the control of the tac promoter. Cultured cells were lysed, followed by centrifugation. The dialyzed supernatants of the cell lysate were loaded directly onto a $15 \mathrm{~mL}$ column of GSH- Sepharose, equilibrated with $20 \mathrm{mM}$ potassium phosphate buffer ( $\mathrm{pH}$ 7.0) containing 1.0 mM EDTA and $1.0 \mathrm{mM} 2$-mercaptoethanol (buffer A). The columns were extensively washed with buffer A, containing $20 \mathrm{mM} \mathrm{KCl}$. The enzymes were eluted with a $50 \mathrm{mM}$ Tris-HCl buffer ( $\mathrm{pH}$ 8.5) containing $10 \mathrm{mM} \mathrm{GSH}$ and dialyzed against buffer A. The purified mutant enzymes (R13A, R13K, R13L) gave a single band on the SDS-PAGE with an apparent $\mathrm{Mr}$ of $25 \mathrm{kDa}$, equivalent to that of the wild type (data not shown). Unless otherwise indicated, all purification procedures were carried out either at $4{ }^{\circ} \mathrm{C}$ or on ice. The mutant enzymes were stored at $-70{ }^{\circ} \mathrm{C}$ until use.

Enzyme activity. Specific activities were determined by mea- suring the initial rates of the enzyme-catalyzed conjugation of GSH with CDNB and ethacrynic acid (ETA), as described by Habig and Jakoby. ${ }^{18}$ Assays were performed in a HITACHI U-2000 double-beam spectrophotometer (Hitachi CO., Tokyo, Japan) at $30{ }^{\circ} \mathrm{C}$ using cuvettes of a $1.0 \mathrm{~cm}$ path length. Initial rates were measured for $5 \mathrm{~min}$, commencing $10 \mathrm{~s}$ after initial mixing. The reaction was initiated by addition of $20 \mu \mathrm{L}$ of $50 \mathrm{mM}$ CDNB or ETA to $860 \mu \mathrm{L}$ of $100 \mathrm{mM}$ potassium phosphate (pH 7.5) containing, in order of addition, $100 \mu \mathrm{L}$ of $50 \mathrm{mM} \mathrm{GSH}$ and $20 \mu \mathrm{L}$ of the enzyme. Nonenzymatic reaction rates served as controls and were subtracted from enzymatic rates. The CDNB and ETA were dissolved in ethanol. The concentration of the ethanol in the reaction mixture $(1.0 \mathrm{~mL})$ was constant at $2 \%(\mathrm{v} / \mathrm{v})$. The GSH was dissolved in $\mathrm{H}_{2} \mathrm{O}$ immediately prior to use and stored in an ice-bath to prevent oxidation. The enzymes were diluted in $20 \mathrm{mM}$ potassium phosphate buffer (pH 7.0) containing 1.0 mM EDTA, 1.0 mM2-mercaptoethanol, and $20 \%$ (v/v) glycerol, to a concentration such that the enzymatic reaction rate was linear with time up to $60 \mathrm{~s}$ after initiation, and up to a $\Delta \mathrm{A} / \mathrm{min}$ of 0.15 . All assays were done in the presence of $0.4 \%(\mathrm{v} / \mathrm{v})$ glycerol. Conditions were: (a) $1.0 \mathrm{mM} \mathrm{CDNB}$, $1.0 \mathrm{mM}$ GSH, $340 \mathrm{~nm}\left(\Delta \varepsilon=9.8 \mathrm{mM}^{-1} \mathrm{~cm}^{-1}\right.$; (b) $0.2 \mathrm{mM}$ ETA, $0.25 \mathrm{mM} \mathrm{GSH}, 270 \mathrm{~nm}\left(\Delta \varepsilon=5.0 \mathrm{mM}^{-1} \mathrm{~cm}^{-1}\right)$. A unit of activity was defined as the amount of enzyme catalyzing the formation of $1.0 \mu$ mole of product per min under the conditions of the specific assay. Specific activity was defined as the units of enzyme activity per mg of protein. Steroid isomerase activity was monitored by the catalyzed isomerization of $\Delta^{5}$-androstene3,17-dione $(0.1 \mathrm{mM})$ to $\Delta^{4}$-androstene-3,17-dione, and was determined spectrophotometrically from the change in absorbance at $248 \mathrm{~nm}\left(\Delta \varepsilon=16.3 \mathrm{mM}^{-1} \mathrm{~cm}^{-1}\right)$ in $100 \mathrm{mM}$ potassium phosphate buffer, $\mathrm{pH} 6.5$, at $30{ }^{\circ} \mathrm{C}$ in the presence of $3.0 \mathrm{mM}$ GSH. The GSH-dependent peroxidase activity was assayed in the presence of $5.0 \mathrm{mM} \mathrm{GSH}$, with $1.5 \mathrm{mM}$ cumene hydroperoxide $\left(\Delta \varepsilon=6.6 \mathrm{mM}^{-1} \mathrm{~cm}^{-1}\right)$ as the substrate, at $30{ }^{\circ} \mathrm{C}$, as previously described. ${ }^{19}$ Protein concentration of the wild type enzyme was determined by measuring the absorbance at $280 \mathrm{~nm}$ as described by Parker ${ }^{20}$ and protein concentration of the mutant determined using a protein assay reagent (Bio-Rad Lab, Hercules, CA, USA) with the wild-type enzyme as a standard protein.

Kinetic studies. Kinetic studies with GSH and electrophilic substrates were carried out at $30{ }^{\circ} \mathrm{C}$ as described by Chen et al.. ${ }^{21}$ Kinetic parameter $\left(K_{\mathrm{m}}\right)$ values were determined under first order conditions at low substrate concentrations with respect to the varied substrate: for GSH with a fixed concentration of $1.0 \mathrm{mM} \mathrm{CDNB}$ or ETA; for CDNB or ETA with a fixed concentration of $2.5 \mathrm{mM} \mathrm{GSH}$. The $k_{\text {cat }}$ values were calculated on the basis of mol dimeric enzyme using a $\mathrm{Mr}$ of 45,000 . Other experimental conditions were identical for determination of specific activities. The $\mathrm{pH}$ dependence of the $k_{\mathrm{cat}} / K_{\mathrm{m}}$ was measured and analyzed according to Kong et al. ${ }^{22}$

Inhibition studies. The inhibitory effects on the activity of the enzyme were measured by preincubating the enzyme with $1.0 \mathrm{mM} \mathrm{GSH}$ and the inhibitor for $2 \mathrm{~min}$ and initiating the reaction by addition of $20 \mu \mathrm{L}$ of $50 \mathrm{mM} \mathrm{CDNB}$ (final concentration, $1.0 \mathrm{mM}$ ). The concentration of inhibitor giving $50 \%$ inhibition $\left(I_{50}\right)$ was determined from the plot of residual activity 
against inhibitor concentration.

\section{Results and Discussion}

Among the various GSTs, the human pi-class (hGST P1-1) has attracted considerable attention as reliable preneoplastic or neoplastic marker enzymes because a number of human tumors have been shown to express raised levels of the hGST P1-1 enzyme. ${ }^{23,24}$ Moreover, the hGST P1-1 has been implicated in the development of tumor resistance towards various anti-cancer drugs. ${ }^{25}$ Thus, studies on the relationship between structure and function of hGST P1-1 provide a rationale for the design of inhibitors and prodrugs to enhance therapeutic indices. In order to elucidate the precise enzyme-substrate interactions responsible for the catalytic properties of GST, the mutant enzymes obtained by directed mutagenesis of Arg13 in hGST P1-1 into Ala, Lys, and Leu were expressed in E. coli and purified to electrophoretic homogeneity by affinity column chromatography. Specific activities and kinetic parameters determined for the purified wild-type hGST P1-1 and mutant enzymes were compared. Four different substrates, CDNB, ETA, cumene hydroperoxide, and $\Delta^{5}$-androstene 3,17-dione were chosen in order to monitor the effects of the mutations on three different types of chemical reactions that the enzyme could catalyze: aromatic substitution; reduction of hydroperoxides; isomerization of carbonyl-containing alkenes.

Effects of point mutations of Arg13 residues on substrate specificity. The initial step in mercapturic acid formation is a conjugation of the foreign compound with GSH, a reaction catalyzed by GSTs for many substrates. ${ }^{26}$ The most general substrate used for the demonstration of multiple forms of GSTs in various biological species is CDNB, and the highly active substrate in class Pi GSTs is ETA. The specific activities of

Table 1. Specific activities for the wild type and mutant enzymes

\begin{tabular}{crrcc}
\hline \multirow{2}{*}{ Enzymes } & \multicolumn{4}{c}{ Substrate specificity $(\mu \mathrm{mol} / \mathrm{min} / \mathrm{mg})$} \\
\cline { 2 - 5 } & \multicolumn{1}{c}{ CDNB } & \multicolumn{1}{c}{ ETA } & CP & Androstenedione \\
\hline Wild type & $76.6 \pm 1.5$ & $1.54 \pm 0.12$ & $3.72 \pm 0.33$ & $78.3 \pm 0.5$ \\
R13A & $4.2 \pm 0.2$ & $0.22 \pm 0.03$ & $3.50 \pm 0.51$ & $58.4 \pm 0.8$ \\
R13K & $50.6 \pm 1.0$ & $0.92 \pm 0.11$ & $4.81 \pm 0.10$ & $368.0 \pm 9.2$ \\
R13L & $30.8 \pm 0.8$ & $1.95 \pm 0.02$ & $2.50 \pm 0.10$ & $35.0 \pm 0.4$
\end{tabular}

CDNB, 1-chloro-2,4-dinitrobenzene; ETA, ethacrynic acid; CP, cumene hydroperoxide; Androstenedione, $\Delta^{5}$-Androstene- 3,17-dione. Values are Means \pm S.D., generally based on $n \geq 5$. the mutant enzymes for GSH conjugations of CDNB and ETA are shown in Table 1. The substitutions of Arg13 with L-Ala resulted in a large decrease in the specific activities to approximately $85-95 \%$ of the wild type. Nevertheless, substitution of Arg13 with L-Lys resulted in a moderate decrease in specific activities. The substitution of Arg13 with L-Leu had a negligible effect on the specific activity toward ETA, but resulted in an approximate $60 \%$ decrease in specific activity toward CDNB. These results suggest that contribution of Arg13 to GSH conjugation activity is highly dependent on the size rather than the positive charge of the side chain at position 13 , and that the contribution of Arg13 in binding is dependent on the nature of the electrophilic substrates.

Organic hydroperoxides are substrates for GSTs. A study involving seven cytosolic homodimeric rat transferases demonstrated that linoleate hydroperoxide and arachidonate hydroperoxide in most cases gave activities comparable to the model substrate cumene hydroperoxide. ${ }^{27}$ The GSH peroxidase activities of the mutants are shown in Table 1. The substitution of Arg13 with L-Ala significantly affected the specific activity, while the substitution of Arg13 with L-Leu resulted in approximately $30 \%$ decreases in specific activity towards cumene hydroperoxide. Nonetheless, the substitution of Arg13 with LLys resulted in approximately a 30\% increase in specific activity. GSTs also possess ketosteroid isomerase activity and catalyze the conversion of $\Delta^{5}$-3-ketosteroids to $\Delta^{4}$-3-ketosteroids. The steroid isomerase activities of the mutants are shown in Table 1. The substitutions of Arg13 with L-Ala and L-Leu resulted in a decrease in specific activity to approximately 25 $55 \%$ of the wild type. However, R13K resulted in approximately a $370 \%$ increase in specific activity toward $\Delta^{5}$-androstene 3,17 dione. These results suggest that contribution of $\mathrm{Arg} 13$ to GSH peroxidase and steroid isomerase activities is highly dependent on the types of GST-catalyzed reactions and on the positive charge rather than the size of the side chain at position 13.

Effects of point mutations of the Arg13 residue on kinetic parameters for GSH conjugation activity. The kinetic parameters of the mutants for GSH-CDNB conjugation were determined under first order conditions at low substrate concentrations with respect to varied substrates (Table 2). The substitution of Arg13 with L-Ala resulted in approximately 2 3-fold increases in $K_{\mathrm{m}}{ }^{\mathrm{GSH}}$ and $K_{\mathrm{m}}{ }^{\mathrm{CDNB}}$, whereas $k_{\text {cat }}$ values were approximately 30 - $60 \%$ smaller than that of the wild type. Conversely, substitution of Arg13 with L-Lys resulted in a 3.6-fold increase in $K_{\mathrm{m}}{ }^{\mathrm{CDNB}}$, whereas the $K_{\mathrm{m}}{ }^{\mathrm{GSH}}$ was similar to that of the wild type. This substitution also resulted in approximately a 7-fold

Table 2. Kinetic parameters for GSH-[1-chloro-2,4-dinitrobenzene] conjugation

\begin{tabular}{|c|c|c|c|c|c|c|}
\hline \multirow{2}{*}{ Enzyme } & \multicolumn{3}{|c|}{ GSH } & \multicolumn{3}{|c|}{ 1-Chloro-2,4-dinitrobenzene } \\
\hline & $K_{\mathrm{m}}(\mathrm{mM})$ & $k_{\text {cat }}\left(\mathrm{s}^{-1}\right)$ & $k_{\text {cat }} / K_{\mathrm{m}}\left(\mathrm{mM}^{-1} \mathrm{~s}^{-1}\right)$ & $K_{\mathrm{m}}(\mathrm{mM})$ & $k_{\text {cat }}\left(\mathrm{s}^{-1}\right)$ & $k_{\mathrm{cat}} / K_{\mathrm{m}}\left(\mathrm{mM}^{-1} \mathrm{~s}^{-1}\right)$ \\
\hline Wild type & $0.16 \pm 0.02$ & $6.3 \pm 0.9$ & 39.4 & $0.65 \pm 0.04$ & $72.6 \pm 1.8$ & 111.7 \\
\hline R13A & $0.34 \pm 0.02$ & $4.5 \pm 0.1$ & 13.2 & $1.99 \pm 0.01$ & $30.1 \pm 1.0$ & 15.1 \\
\hline R13K & $0.20 \pm 0.01$ & $42.8 \pm 1.1$ & 214.0 & $2.32 \pm 0.10$ & $96.2 \pm 3.5$ & 41.5 \\
\hline $\mathrm{R} 13 \mathrm{~L}$ & $0.06 \pm 0.01$ & $3.0 \pm 0.5$ & 50.0 & $17.5 \pm 2.1$ & $11.1 \pm 1.0$ & 0.6 \\
\hline
\end{tabular}

Values are Means \pm S.D., generally based on $n \geq 5$. 
Table 3. Kinetic parameters for GSH-[Ethacrynic acid] conjugation.

\begin{tabular}{|c|c|c|c|c|c|c|}
\hline \multirow{2}{*}{ Enzyme } & \multicolumn{3}{|c|}{ GSH } & \multicolumn{3}{|c|}{ Ethacrynic acid } \\
\hline & $K_{\mathrm{m}}(\mathrm{mM})$ & $k_{\text {cat }}\left(\mathrm{s}^{-1}\right)$ & $k_{\mathrm{cat}} / K_{\mathrm{m}}\left(\mathrm{mM}^{-1} \mathrm{~s}^{-1}\right)$ & $K_{\mathrm{m}}(\mathrm{mM})$ & $k_{\text {cat }}\left(\mathrm{s}^{-1}\right)$ & $k_{\mathrm{cat}} / K_{\mathrm{m}}\left(\mathrm{mM}^{-1} \mathrm{~s}^{-1}\right)$ \\
\hline Wild type & $0.15 \pm 0.04$ & $31 \pm 8$ & 2.1 & $0.18 \pm 0.07$ & $112 \pm 8$ & 6.2 \\
\hline $\mathrm{R} 13 \mathrm{~A}$ & $2.62 \pm 0.06$ & $3 \pm 0.2$ & 0.01 & $0.18 \pm 0.03$ & $7 \pm 2$ & 0.4 \\
\hline R13K & $0.12 \pm 0.01$ & $30 \pm 6$ & 2.5 & $0.12 \pm 0.01$ & $64 \pm 6$ & 5.3 \\
\hline R13L & $0.15 \pm 0.05$ & $5 \pm 0.5$ & 0.3 & $0.01 \pm 0.001$ & $127 \pm 9$ & 127.0 \\
\hline
\end{tabular}

Values are Means \pm S.D., generally based on $n \geq 5$.

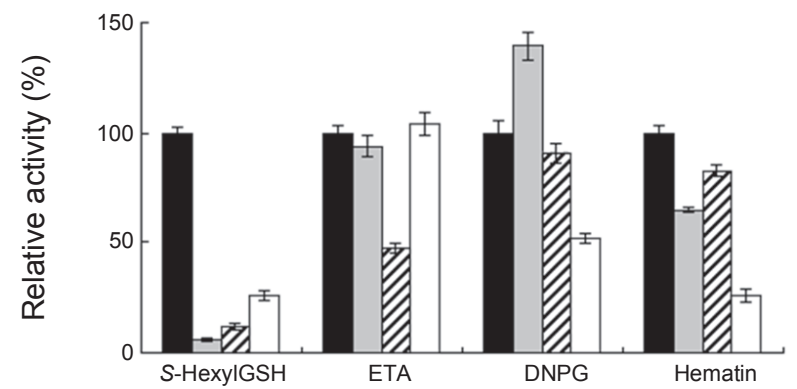

Figure 2. Effect of inhibitors on the GSH conjugation activity of the wild type and mutant enzymes. Wild type (black); R13A (gray); R13K (hatched); R13L (white). The inhibitors were: (a) $S$-hexylGSH $\left(\times 10^{-1}\right.$ $\mu \mathrm{M})$; (b) ethacrynic acid (ETA, mM); (c) $S$-(2,4-dinitrophenyl)GSH (DNPG, $\mu \mathrm{M})$; (d) hematin $\left(\times 10^{-1} \mu \mathrm{M}\right)$. Values are Means \pm S.D., generally based on $\mathrm{n} \geq 5$.

increase in $k_{\text {cat }}$ toward GSH. The substitution of $\operatorname{Arg} 13$ with L-Leu resulted in approximately a $2 \sim 7$-fold decrease in $K_{\mathrm{m}}{ }^{\mathrm{GSH}}$ and $k_{\text {cat }}$ values, whereas $K_{\mathrm{m}}{ }^{\mathrm{CDNB}}$ values were approximately 2 7-fold larger than that of the wild type. From these results, the positive charge at position 13 may be able to participate in catalysis of the GSH-CDNB conjugation reaction, while introduction of the larger side chain at position 13 resulted in a stronger affinity (L-Leu > L-Lys, L-Arg > L-Ala) toward GSH.

Table 3 summarizes the kinetic parameters of the mutants for the GSH-ETA conjugation. The substitutions of Arg13 with L-Ala resulted in approximately 17-fold increases of $K_{\mathrm{m}}^{\mathrm{GSH}}$ values, whereas the $K_{\mathrm{m}}{ }^{\text {ETA }}$ values were similar to that of the wild type. On the other hand, substitutions of Arg 13 with L-Leu resulted in approximately 18 -fold decreases in $K_{\mathrm{m}}^{\text {ETA }}$ values, whereas the $K_{\mathrm{m}}{ }^{\mathrm{GSH}}$ values were similar to that of the wild type. The substitution of Arg13 with L-Lys scarcely affected the kinetic parameters for GSH-ETA conjugation. These results suggest that introduction of larger side chains at position 13 results in a stronger affinity (L-Leu > L-Lys > L-Arg, L-Ala) towards ETA.

In order to further probe the functional properties of the mutant enzymes, the inhibition parameters $\left(I_{50}\right)$ of various inhibitor types, $S$-hexylGSH, ETA, $S$-(2,4-dinitrophenyl)GSH, and hematin for GSH-CDNB conjugating activity were determined under standard assay conditions (Fig. 2). Substitution of Arg 13 resulted in approximately $4 \sim 17$-fold decreases in the $I_{50}$ values of $S$-hexylGSH, a competitor of GSH. Substitution of Arg 13 with L-Ala resulted in a 2.4-fold increase in the $I_{50}$ value of ETA, which competes with CDNB as an electrophilic substrate.
Nevertheless, substitution of Arg 13 with L-Lys resulted in a 2.1 -fold decrease. The $I_{50}$ value for R13L was similar to that of the wild type. The $I_{50}$ values of $S$-(2,4-dinitrophenyl)GSH, a conjugation product of GSH with CDNB, for R13K and R13L were lower than the wild-type. Notwithstanding, the $I_{50}$ value for R13A was slightly higher than the wild type value by nearly 1.4 -fold.

GST is known to function as a ligandin that binds non-substrate hydrophobic ligands, such as heme, billirubin, steroids, and vitamin K. Hydrophobic interactions are considered important for the binding of these ligands. ${ }^{1}$ However, since many of the ligands possess anionic groups such as carboxylates, electrostatic interaction between the anionic groups of the ligands and the cationic groups of GST, such as the side chains of the Arg and Lys residues, might also be involved in the function as ligandins. The $I_{50}$ value of hematin, a nonsubstrate ligand, for R13L was significantly lower than that of the wild type, nearly 4-fold (Fig. 2). On the other hand, the $I_{50}$ values of hematin for R13A and R13K were similar to those of the wild type, suggesting that contribution of $\operatorname{Arg} 13$ in the binding of hematin is highly dependent on the size rather than the positive charge of the side chains at position 13. Reinemer et al. suggested that an Arg residue serves as an anionic recognition site for GST and that there exists the "ligandin", or a "nonsubstrate" binding site, at the interface between the two subunits. ${ }^{8}$ Nishihira et al. suggested that binding of the hydrophobic ligand to GST produces a remarkable conformational change of the active center of the enzyme. ${ }^{28}$ Taken together, although the Arg 13 residue is thought not to interact with hematin directly, substitution of this residue with L-Leu is speculated to induce a conformational change in the active site.

Dependence of kinetic parameters on $\mathbf{p H}$. Enhancement of the nucleophilicity of the thiol group in GSH by lowering the $\mathrm{p} K_{\mathrm{a}}$ value is considered a major role of GSTs in catalyzing the formation of the GSH-conjugate. The $\mathrm{pH}$ dependence of the $k_{\mathrm{cat}} / K_{\mathrm{m}}$ value has previously been studied for the wild-type enzyme and for mutant $\mathrm{Y} 7 \mathrm{~F} .{ }^{22}$ The $\mathrm{p} K_{\mathrm{a}}$ value of the thiol group of GSH bound in wild-type hGST P1-1 was approximately $2.8 \mathrm{pK}$ units lower than the value (9.1) of free GSH in aqueous solution, whereas the value for mutant $\mathrm{Y} 7 \mathrm{~F}$ was approximately $2.4 \mathrm{pK}$ units higher than the value (6.3) of the wild-type enzyme. The interaction between the hydroxyl group of Tyr7 and the thiol group was essential to the GSH conjugating reaction by lowering the $\mathrm{p} K_{\mathrm{a}}$ value. Similar studies were made on mutants $\mathrm{R} 13 \mathrm{~A}, \mathrm{R} 13 \mathrm{~K}$, and R13L in this investigation. The $k_{\text {cat }} / K_{\mathrm{m}}{ }^{\mathrm{CDNB}}$ 


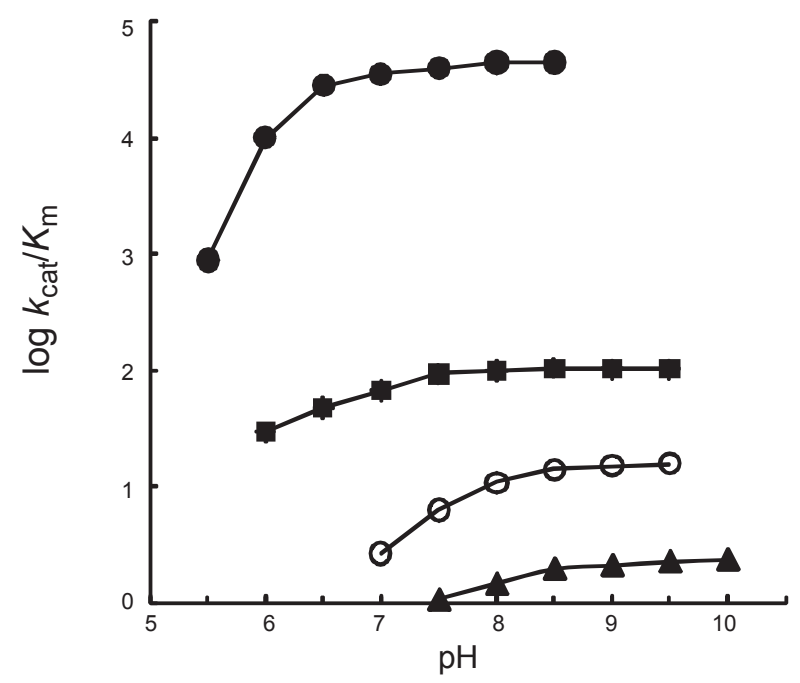

Figure 3. Dependence of $\log k_{\text {cat }} / K_{\mathrm{m}}$ values on $\mathrm{pH}$. The kinetic parameter of the wild type and mutant enzymes for conjugation of GSH with CDNB were determined under the conditions of saturating GSH (2.0 $\mathrm{mM})$ and variable concentrations of CDNB $(0.1-1.0 \mathrm{mM})$. - $\bullet-$, Wild type; -^-, R13A; ---, R13K; -o-, R13L.

values of mutant enzymes for GSH-CDNB conjugation were determined at various $\mathrm{pH}$ values with a large excess of GSH. The $\mathrm{pH}$ dependence of the $k_{\mathrm{cat}} / K_{\mathrm{m}}{ }^{\mathrm{CDNB}}$ values of the wild type and mutant enzymes are shown in Fig. 3 and compared with the value previously determined for the wild type enzyme. ${ }^{22}$ From the plots of $\log \left(k_{\mathrm{cat}} / K_{\mathrm{m}}{ }^{\mathrm{CDNB}}\right)$ against $\mathrm{pH}$, the $\mathrm{p} K_{\mathrm{a}}$ values of the thiol group of GSH bound in R13A, R13K, and R13L were estimated to be $1.8,1.4$, and $1.8 \mathrm{p} K$ units higher than the $\mathrm{p} K_{\mathrm{a}}$ value (6.3) of the wild type enzyme, respectively. Removal of the basic side-chain functionality, as in mutants R13A and $\mathrm{R} 13 \mathrm{~L}$, caused an increase in the $\mathrm{p} K_{\mathrm{a}}$ values of the thiol group of GSH bound in the enzyme to 8.1 (Fig. 3). These $\mathrm{p} K_{\mathrm{a}}$ values suggest that replacement of Arg 13 with L-Ala and L-Leu affect the interaction between the thiol groups and Tyr7 through distortion of the orientation of the GSH bound in the enzyme. When Arg13 was replaced by Lys, a residue with basicity lower than $\mathrm{Arg}$, the $\mathrm{p} K_{\mathrm{a}}$ value was increased to 7.7, 0.4 units higher than in mutant R13A and R13L, demonstrating the contribution of the Arg13 guanidinium group to the active site electrostatic field.

These results were supported by studies on the three-dimensional structures of GST. The three-dimensional structure of the human GST P1-1, in complex with the inhibitor ETA, implicated that the inhibitor sits in a hydrophobic pocket lined with the side chains of Tyr7, Phe8, Pro9, and Val10, while the aliphatic portions of Arg13, Val35, Ile104, and Tyr108, and the carboxylic acid moiety of the inhibitor forms a hydrogen bond to the $\mathrm{N}_{\varepsilon}$ atom of $\mathrm{Arg} 13{ }^{29}$ Moreover, two electrostatic interactions were observed in hGST P1-1[V104] with a GSH conjugate of (+)-anti-7,8-dihydroxy-9,10-oxy-7,8,9,10-tetrahydrobenzo $[\alpha]$ pyrene (GSBpd), including a hydrogen bond between the hydroxyl group of Tyr7 and the sulfur atom of GSH and a direct hydrogen bond between $\operatorname{Arg} 13$ and the hydroxyl group of the Bpd moiety of GSBpd, demonstrating participation of Arg13 in catalysis. ${ }^{13}$ Similarly, Björnestedt et al. reported mutations of the Arg15 residue (the counterpart of Arg13 in GST P1-1) in human class Alpha GST A1-1. ${ }^{30}$ They suggested that the contributions provided by Arg15 in human GST A1-1 involved hydrogen bonding to the sulfur atom of GSH and the creation of an electrostatic potential in the G-site that favors ionization of enzyme-bound GSH. Taken together, we conclude that the contribution of evolutionally conserved Arg13 in substrate binding is highly dependent on the nature of the electrophilic substrates and in the catalytic mechanism that stabilizes the GSH thiolate through hydrogen bonding. Further accurate elucidation of the multifunctional role in GST P1-1 catalysis of this residue requires a detailed kinetic study for GSH peroxidase and steroid isomerase activities and three-dimensional structure analysis of these mutant enzymes.

Acknowledgments. This research was supported by the Chung-Ang University Research Grants in 2010.

\section{References}

1. Mannervik, B.; Danielson, U. H. CRC Crit. Rev. Biochem. 1988, 23,283 .

2. Fahey, R. C.; Sundquist, A. R. Adv. Enzymol. Rel. Areas Mol. Biol. 1991, 64, 1 .

3. Armstrong, R. N. Chem. Res. Toxicol. 1991, 4, 131.

4. Armstrong, R. N. Chem. Res. Toxicol. 1997, 10, 2.

5. Mannervik, B.; Awasthi, Y. C.; Board, P. G.; Hayes, J. D.; Ilio, C.; Ketterer, B.; Listowsky, I.; Morgenstern, R.; Muramatsu, M.; Pearson, W. R.; Pickett, C. B.; Sato, K.; Widersten, M.; Wolf, C. R. Biochem. J. 1992, 282, 305.

6. Ji, X.; Zhang, P.; Armstrong, R. N.; Gilliland, G. L. Biochemistry 1992, 31, 10169 .

7. Ji, X.; Von Rosenvinge, E. C.; Johnson, W. W.; Tomarev, S. I.; Piatigorsky, J.; Armstrong, R. N.; Gilliland, G. L. Biochemistry 1995, 34, 5317.

8. Reinemer, P.; Dirr, H. W.; Ladenstein, R.; Schäffer, J.; Gallay, O.; Huber, R. EMBO J. 1991, 10, 1997.

9. Sinning, I.; Kleywegt, G. J.; Cowan, S. W.; Reinemer, P.; Dirr, H. W.; Huber, R.; Gilliland, G. L.; Armstrong, R. N.; Ji, X.; Board, P. G.; Olin, B.; Mannervik, B.; Jones, T. A. J. Mol. Biol. 1993, 232, 192.

10. Wilce, M. C. J.; Board, P. G.; Feil, S. C.; Parker, M. W. EMBO J. 1995, 14, 2133.

11. Reinemer, P.; Dirr, H. W.; Ladenstein, R.; Huber, R. J. Mol. Biol. 1992, 217, 214.

12. Ji, X.; Tordova, M.; O’Donnell, R.; Parsons, J. F.; Hayden, J. B.; Gilliland, G. L.; Zimniak, P. Biochemistry 1997, 36, 9690.

13. Ji, X.; Blaszczyk, J.; Xiao, B.; O’Donnell, R.; Hu, X.; Herzog, C.; Singh, S. V.; Zimniak, P. Biochemistry 1999, 38, 10231.

14. Koh, J.-U.; Cho, H.-Y.; Kong, K.-H. Bull. Korean Chem. Soc. 2007, 28,772 .

15. Schramm, V. L.; McCluskey, R.; Emig, F. A.; Litwack, G. J. Biol. Chem. 1984, 259, 714.

16. Kano, T.; Sakai, M.; Muramatsu, M. Cancer Res. 1987, 47, 5626.

17. Kong, K.-H.; Inoue, H.; Takahashi, K. Biochem. Biophys. Res. Commun. 1991, 181, 748.

18. Habig, W. H.; Jakoby, W. B. Methods Enzymol. 1981, 77, 398.

19. Flohè, L.; Günzler, W. A. Methods. Enzymol. 1985, 105, 114.

20. Parker, M. W.; Bello, M. L.; Federici, G. J. Mol. Biol. 1990, 213, 221.

21. Chen, W.-L.; Haieh, J.-C.; Hong, J.-L.; Tsai, S.-P.; Tam, M. F. Biochem. J. 1992, 286, 205.

22. Kong, K.-H.; Takasu, K.; Inoue, H.; Takahashi, K. Biochem. Biophys. Res. Commun. 1992, 184, 194.

23. Tsuchida, S.; Sato, K. CRC Crit. Rev. Biochem. Mol. Biol. 1992, $27,337$. 
24. Hayes, J. D.; Pulford, D. J. Crit. Rev. Biochem. Mol. Biol. 1995, 30, 445.

25. Morgan, A. S.; Ciaccio, P. J.; Tew, K. D.; Kauvar, L. M. Cancer Chemother. Pharmacol. 1996, 37, 363.

26. Mannervik, B. Adv. Enzymol. Rel. Areas Mol. Biol. 1985, 57, 357.

27. Ketterer, B.; Tan, K. H.; Meyer, D. J.; Coles, B. In Glutahtione STransferase and Carcinogenesis; Taylor \& Frabcis: London, 1987; p 149.

28. Nishihira, J.; Ishibashi, T.; Sakai, M.; Tsuda, S.; Hikichi, K. Arch. Biochem. Biophys. 1993, 302, 128.

29. Oakley, A. J.; Rossjohn, J.; Bello, M. L.; Caccuri, A. M.; Federici, G.; Paker, M. W. Biochemistry 1997, 36, 576.

30. Björnestedt, R.; Stenberg, G.; Widersten, M.; Board, P. G.; Sinning, I.; Jones, T. A.; Mannervik, B. J. Mol. Biol. 1995, 765. 